\title{
Mutagenicity assessment of aerosols in emissions from domestic combustion processes
}

\author{
Nuno Canha ${ }^{1,2}$ - Isabel Lopes ${ }^{3}$ - Estela Domingos Vicente ${ }^{2}$ - Ana M. Vicente $^{2}$. \\ Benjamin A. Musa Bandowe ${ }^{4} \cdot$ Susana Marta Almeida ${ }^{1}$ - Célia A. Alves ${ }^{2}$
}

Published online: 20 April 2017

(C) Springer-Verlag Berlin Heidelberg 2017

\begin{abstract}
Domestic biofuel combustion is one of the major sources of regional and local air pollution, mainly regarding particulate matter and organic compounds, during winter periods. Mutagenic and carcinogenic activity potentials of the ambient particulate matter have been associated with the fraction of polycyclic aromatic hydrocarbons $(\mathrm{PAH})$ and their oxygenated (OPAH) and nitrogenated (NPAH) derivatives. This study aimed at assessing the mutagenicity potential of the fraction of this polycyclic aromatic compound in particles $\left(\mathrm{PM}_{10}\right)$ from domestic combustion by using the Ames assays with Salmonella typhimurium TA98 and TA100. Seven biofuels, including four types of pellets and three agro-fuels (olive pit, almond shell and shell of pine nuts), were tested in an automatic pellet stove, and two types of wood (Pinus pinaster, maritime pine, and Eucalyptus globulus, eucalypt) were burned in a traditional wood stove. For this latter appliance, two combustion phases-Devolatilisation and flaming/ smouldering-Were characterised separately. A direct-acting
\end{abstract}

Responsible editor: Philippe Garrigues

Nuno Canha

nunocanha@ctn.tecnico.ulisboa.pt

1 Centro de Ciências e Tecnologias Nucleares, Instituto Superior Técnico, Universidade de Lisboa, Estrada Nacional 10, Km 139.7, 2695-066 Bobadela LRS, Portugal

2 Department of Environment and Planning, CESAM - Centre for Environmental and Marine Studies, University of Aveiro, 3810-193 Aveiro, Portugal

3 Department of Biology and CESAM — Centre for Environmental and Marine Studies, University of Aveiro, Campus de Santiago, 3810-193 Aveiro, Portugal

4 Institute of Geography, University of Bern, Hallerstrasse 12, 3012 Bern, Switzerland mutagenic effect for the devolatilisation phase of pine combustion and for both phases of eucalypt combustion was found. Almond shell revealed a weak direct-acting mutagenic effect, while one type of pellets, made of recycled wastes, and pine (devolatilisation) presented a cytotoxic effect towards strain TA100. Compared to the manually fired appliance, the automatic pellet stove promoted lower polyaromatic mutagenic emissions. For this device, only two of the studied biofuels presented a weak mutagenic or cytotoxic potential.

This article was originally intended as an invited contribution to the special issue Biomonitoring of atmospheric pollution: possibilities and future challenges but was inadvertently published prematurely in Environmental Science and Pollution Research Volume 23, Issue 11, pp 10799-10807, DOI 10.1007/s11356-016-6292-2. 